\title{
XXIV. Papers relating to a design for the new London Bridge, on the principle of cementitious architecture:-exhibited to the committee of the house of commons, on the 11th of April 1823
}

\author{
John White Esq.
}

To cite this article: John White Esq. (1832) XXIV. Papers relating to a design for the new London Bridge, on the principle of cementitious architecture:-exhibited to the committee of the house of commons, on the 11th of April 1823, Philosophical Magazine Series 2, 11:63, 183-194, DOI: $10.1080 / 14786443208647721$

To link to this article: http://dx.doi.org/10.1080/14786443208647721

曲 Published online: 25 Jun 2009.

Submit your article to this journal $₫$

Џ Article views: 2

Q View related articles $\sqsubset$ 
city, although the exact amount was not numerically ascertained. This specimen was preserved unbroken. Upon the whole, however, it has the advantage of the oaks in strength, except those marked No. 7 and 8 , which were remarkably fine specimens; but it will be found by referring to Barlow's Essay to greatly exceed the strength of oak in general.

The results of the oak experiments seem certainly to be in favour of the fast grown. "These experiments," Mr. Withers observes," throw new light upon the subject, and lead to the most important conclusions. They prove not only that fast growing timber is superior in quality to that of slower growth, but that by the constant application of manure to the roots of trees planted even in good soil, nearly double the quantity of timber may be obtained in the same period, while its strength instead of being diminished will be thereby increased."

XXIV. Papers relating to a Design for the Nero London Bridge, on the Principle of Cementitious Architecture:-exhibited to the Committee of the House of Commons, on the 11 th of April 1823. By JoH WhITE, Esq.**

$$
\text { [With a Plate.] }
$$

Contents.-Mr. White's Letter to the Comptroller of the Estates of London Bridge.-Mr. Newman to Mr. White--Mr. White to Dr. Gregory. - General Observations on the Designs for London Bridge--Dr. Gregory's Reply.-Dr. Gregory's Observations.-Mr. White to the Editor of the Quarterly Journal.-Account of Experiments on Cements,-Inference from these Experiments.-Extract from the Memoirs of Savary, Duke of Rovigo.

\section{To the Comptroller of the Estates of London Bridge.} Sir, -

BEG leave to submit to your notice the following sugges1 tions upon the subject of the removal of London Bridge, to which the mind of the public is at the present time so much directed, premising that I agree with the Second Report of the Committee of the House of Commons, that a work of such public importance as the plan of 1814 should not be undertaken without the greatest and most unequivocal certainty of ultimate success, and that it is, as the Committee conceived, extremely doubtful whether a New Bridge would not ultimately be found less expensive than the proposed alteration.

The River Thames is considered as a river having an artificial obstacle, producing a rapid and extremely irregular fall

- Communicated by the Author.-Mr. Telford's Report, in 1823, on the effects on the Thames of rebuilding London Bridge, and another paper on the same subject, will be found in Phil. Mag. vol. Kxii. p. 21, 28 . 
at London Bridge, differing only from rapids as generally understood, on account of its double action, viz. upwards and downwards according to the state of the tide whether ebbing or flowing; the ebbing tide producing the more violent rapid, from two causes, the one an increase of the water from the upper country, the other the greater ease of discharge from the widening of the river and its greater depth towards its mouth.

The City of London has most judiciously improved the rapids of the river upwards as far as their conservancy of the navigation extends, by constructing locks and weirs.

It seems somewhat singular that the improvement of the rapid at London Bridge should not have been publicly discussed otherwise than by investigating the question whether the removal of the dam of the Bridge itself were a safe and prudent measure.

Having been much impressed with the necessity of an ample consideration of the measure in all its bearings, I visited Holland in July last, conceiving that before I communicated my sentiments on the subject, it would be desirable I should make personal observations upon the large Dutch sluices, particularly that of Catwyk, which is situated at the ancient discharge of the River Rhine into the sea at a part of the coast where the ocean is much agitated, and where there is much difficulty of approach. The lockage I found to be of a different construction to that of the locks in England, but adapted to the passage of vessels, and easily worked.

By the determination of the Committee to prepare plans for rebuilding London Bridge, it must be obvious that the intended scheme of a five-arched bridge is not calculated on a system of regulating the tide, but on the contrary, favours the conclusion that the removal of the dam of London Bridge is the more desirable step, as its reconstruction will afford a water way of 690 feet, the minimum prescribed by their prospectus for designs.

I am of opinion that the fears entertained by many persons of the increase of the height of spring tides in the river above the bridge are greater than they reasonably ought to be, because no alteration of the river at London will increase the height of the tide at the Nore, which height when excessive is caused by sudden changes of the wind, and which in its endeavour to equalize itself, flows up the channel of the river, and so causes extraordinary high tides therein. An opposite effect is produced by the wind, causing extreme low water in the river, especially when there is little upland water. This extreme low water is probably more detrimental to the convenient navigation of London; for it is a very common complaint with 
with bargemen that they cannot get their craft to float, as they term it. This last consideration is very important in determining the question, whether London Bridge is beneficial or otherwise, as it acts as a dam, or an imperfect regulating lock.

Supposing the new bridge, or the present bridge to be assimilated to the sluice at Catwyk, but regulating in a different mode and degree the fall and the quantity of water issuing through it, would its operation be advantageous or detrimental? This question appears to me worthy of discussion in several points of view : -

First. Whether the navigation upwards is improveable by admitting a greater or less quantity of water at London Bridge, or at any higher part of the river, according to its fuller or emptier state?

Secondly. Whether the passage through the bridge itself is capable of improvement by lockage?

Thirdly. Can the present bridge be rendered equal to such a system, and at the same time improved in character and utility as to the passage over it?

Fourthly. Can a new bridge be constructed to have these advantages?

Fifthly. Would the health of the metropolis, as it relates to the current of air caused by the tides, and the discharge of its sewage waters, be injured by the measure?

Sixthly. Taking it for granted that a regulation of the flux and reflux of the tide is beneficial, ought such a regulation to be a partial one or otherwise?

The River Thames receives no considerable accession of water between London Bridge and the first lock on its course at Teddington, excepting that arising from the flowing tide, and from the rivers Colne, Wandle, Brent, and a few smaller streams which do not drain a large district of country, and of which the waters can easily be ascertained, as well as the magnitude of the lockage which would be required to transmit them regularly into the Pool below London Bridge.

The lock and weir at Teddington might afford data which would be useful in the above calculation; but would not of themselves authorize the conclusion, that the navigation of the river above Westminster would be improved by regulating the flow of water at London Bridge, or at any rate by reducing its progress, which is perhaps essential to carry up the craft until they are in a situation to be towed by horses; though such regulation might be essential or beneficial in improving the passage through London Bridge, and the parts immediately upwards.

The consideration of the preceding six points may possibly N.S. Vol. 11. No. 63. March 1832. 2 B throw 
throw some light on the subject if they have not before been agitated. I am willing to contribute with the greatest pleasure my further ideas, which from an attention to the matter are somewhat matured, and which I am nearly prepared to communicate in a more perfect form.

I have the honour to be, Sir, your most humble servant, New Road, Marylebone, Jan. 14, 1823. JoHN WHITE.

\section{To John White, Esq.}

Sir,-Your favour of the 14th instant, relative to the improvement of the River Thames at London Bridge, has been laid before the Committee for letting the Bridge House Estates, who have directed me to inform you, that as soon as they shall have awarded the premiums for the designs furnished for rebuilding London Bridge, which will in all probability be done in a few days, they will take your letter into consideration.

I have the honour to be, Sir, your obedient servant,

Sion College Gardens, Jan. 22, 1823.

R. F. Newman.

\section{To Dr. Olinthus Gregory, Royal Military Academy, Woolwoich.}

$\mathrm{Sir},-\mathrm{My}$ brother has had the goodness to introduce to your observations the accompanying papers respecting London Bridge, which were written to elucidate my design for the new structure.

I am desirous of obtaining the judgement of a [previous] stranger [to my plans] of your well known abilities, and I shall consider it an eminent favour if you would condescend to communicate to me your sentiments thereon at an early period, whether for my private satisfaction, or to show to my friends, as may be agreeable to yourself.

I have the honour to be, with the greatest respect,

Sir, your must humble servant,

New Road, Marylebone, March 3, 1823. JoHN White.

IV. On the Plans for erecting a New London Bridge, distinguished by the Signature "Amicus."

The author of the accompanying plans (marked [Plate II.] $1,2,3,4,5)$ is of opinion that in the construction of bridges the following particulars deserve especial attention, viz.

First. The pressure or gravitation of the component materials.

Secondly. The cohesion of those materials, the principles of gravitation and cohesion being, in practice, in many respects essentially different.

A bridge depending principally on the gravity, and consequently on the pressure or equilibration of its constituent parts, in order to be perfectly durable, must be formed of the most 
costly materials, must be contrived with the greatest skill, and must be executed with the utmost nicety; yet such a bridge will from its very nature be ill adapted for great adventitious and unequal weights; and a design upon that principle has not been pursued, but one on the cohesive chosen.

If we reflect upon the durability of edifices, and judge from the remains of former times, we shall perceive that cohesive buildings are of three distinct formations :

The first denominated the "Cyclopian," and considered to be the most ancient of Grecian erections, has the stone or marble so exquisitely wrought where the joints are made, or otherwise so fitted as to form an almost homogeneous substance*.

The second, the "Cementitious" consists of small materials of almost every form and quality, so well united as in fact to approach to a perfectly solid congruent body.

The third, the "Bonded," may be seen in many works, apparently of more recent date, having squared stone and marble. These sometimes remain well united, and at other times are so separated and injured by the action of the atmosphere and vegetation, that in fact they cease to be, if ever they actually were, adhesive to each other.

Of these three methods of building, the Cyclopian is now hardly practicable, on account of the vast labour it would require. The writer does not attempt to recommend its adoption, but alludes to it, because whoever contemplates the peculiarity of this mode of structure may better understand his ideas. He therefore proceeds to advert to the system of uniting substances of various forms and of small dimensions by the intervention and assistance of cement, which appears to him particularly desirable not only on account of superior durability, but also on account of greater ease and rapidity of execution at a comparatively small expense. The question is whether we possess a perfect uniting body.

The ancient buildings in this country as well as in others, sufficiently manifest the indurating nature of lime + . Modern discoveries have introduced various preparations of it and combinations with it, which lead us to conclude that we are tolerably well acquainted with its judicious employment. The Dutch 'Terras is unquestionably durable and excellent. Parker's and Mulgrave’s cements $\ddagger$ possess eminently the setting

* It is denied [by some] that cement is at all used.

+ This may in some measure be doubted, if Waterloo Bridge is to serve as an example; for in it the cement or mortar is so ill compounded, as to suffer the lime to escape through the arches, where it forms incrustations on the outside of the stone. $\ddagger$ Or Atkinson's.

power ; 
power; and the Pozzolano the greatest disposition to indurate with time.

The third mode of construction, viz. that of Bond, must depend upon the strength, durability and form of the stone, as well as the workmanship. If the work is laid in horizontal beds, parallelopipedons of the proportions of 5,10 and 2 will make excellent bond; and the same forms laid vertically will answer for the arches, if radiated. It must be evident, however, that these stones, whatever their sizes may be, must have evenly tooled surfaces, or cement, to make the joints incompressible after the stones are set; perhaps where the stones are vertically placed, fint dowels ought to be employed.

In order to apply the preceding observations to the designs, it may be proper to explain that the elevation $A$ is drawn with little distinction in the stone-work, upon the presumption of our possessing a proper cement, and that there is no difficulty in obtaining a sufficient quantity, which indeed appears unquestionable, if Parker's or Lord Mulgrave's be employed where immediate adhesion is required, and Pozzolano where time for setting can be allowed. None of those cements will shrink; they attach well to each other, to stone, and to brick; so that if the stone or brick-work is well set and fitted in, an almost homogeneous structure will be obtained. Admitting this to be the case, the form of the edifice itself can only be so far important as that it should afford sufficient substance to be united capable of carrying its own weight, and the adventitious weight which public traffic may impose upon it; the shape and size of the united materials not being of much importance, provided they do not approach to regular squares, or that rounded bodies are not introduced in too large proportions. Perfectly vitrified brick may be equally employed with stone, but not to form the external face, which is supposed to have a moderately tooled plain-work surface, and the arch-stones following the curve as secants to the circumference.

The second design is upon the third mentioned formation, viz. that of Bond, and is arranged so as to permit an interweaving of the stones without endangering their being crushed by the incumbent weight. It is obvious that the thinner the stones are in their beds, the greater will be the bond; and the better tooled and the fairer the surfaces where they meet, the less likely will the stones be to ride, and consequently to be broken*.

Much

* Other modes of obtaining bond have been employed, besides that derived from the form of stones; particularly the introduction of metallic 
Much consideration has been bestowed upon the shape of arches and arch-stones; but if the observations be correct, attention has been directed too largely to what is called the equipollence of arches, and too little to the intersection and perfect union of the materials themselves. Were the whole structure of a bridge completely united in its parts and any adequate foundation obtained, it would hardly be possible that it should fail even in the degree which Westminster or Blackfriars Bridges already have done. In Westminster Bridge the arch-stones are larger and less numerous than the filling in of the spandrels, though both are radiated. In Blackfriars only the arch-stones are radiated, the filling in is in nearly horizontal courses, and consequently not bonded with the arch-stones.

It may seem very difficult where labour is so dear as it is in England, to work stones with the fair faces suggested; but there can be no doubt that this may be easily accomplished by the employment of a steam-engine for the purpose of tooling.

Having made these observations on the cementitious and bonded designs, a brief explanation may be necessary of the situation of the bridge. This is perhaps sufficiently shown by the plan, which represents a nearly square space on the London side, and a lengthened parallelogram on the Southwark; the houses to be removed being shown by a fainter shade of ink than the old buildings, which are not interfered with, a full detail of the buildings to be removed being a distinct matter from the construction of the bridge itself.

Proceeding to the aspect of the bridge*, the data given by the Committee have limited in a certain degree the views of the writer. As it is wished to make the expense of the structure as small as may be consistent with the dignity of the work, the balustrade so frequently employed in England is wholly omitted. It is in fact no necessary part, and in itself an obstruction to the passenger; yet as some decoration is desirable, four metræ are introduced, one at each corner of the bridge, on which may be inscribed the distances to various parts of the kingdom as they respectively bear on each quarter; and

plugs and cramps, and dovetails and joggles cut in the stones themselves: but all these appear inferior to a judicious interlacing of the materials themselves.

* The writer would not have chesen for this situation a bridge of five arches, but preferred one of seven arches, which would have possessed every advantage necessary as a water way, and be without the excessive span of a five-arched bridge. 
an ornamental figure is introduced at each pier on a base elevated above the high-water mark.

Simple segments of circles are used for the form of the arches; first, on account of the imperfection which appears in the outline of elliptical arches when viewed from below; and secondly, because the same centering may be used in their erection.

Elliptical openings are shown over each pier, not only for the purpose of saving materials, but weight, and in order to give lightness and elegance of effect.

The faces of the bridges are proposed to be of tooled stone, without chamfering or any roughness, which retains the dust or smoke.

With regard to the stone itself, the cementitious or adhesive bridge may be of best Kentish rag, best Dartmoor [granite], best Aberdeen [granite], selected Portland stone or brick mixed, all in small sizes. The only essential point is, that there should be an uniform external facing of best rag or granite, well united with the internal materials. The stones of the bonded bridge should be the shapes described by the drawings, and of dimensions to lie in equal layers or beds.

As to the pavements, the carriage way should be made with best granite stones of the proportions following; viz. 10 to 14 inches, by $4 \frac{1}{2}$ to 5 inches on the face, and 12 inches deep; the foot pavements laid with six-inch granite slabs.

The centering is suggested to be of cast-iron ribs supported by piles until the arches with part of the superstructure be completed, these ribs to be removed as the work advances.

There now appears so much science in forming caissons and coffre-dams, that it only remains to notice that the double coffre-dam appears to the author essential in the situation pointed out, on account of the rapidity of the current; the interval between the piling to be filled with the toughest clay intermixed with gravel, and well rammed. As to the expense, the length of the piles must determine the amount in a great degree, and therefore it would be imprudent to offer any calculation thereon, without an opportunity of making trial of the bed of the river.

As to the Expense of the Coffre-dam.-The expense of the coffre-dams cannot be estimated without drawing several proof piles; the timber and workmanship can hardly be less than 10l. per load for best Dantzic, Memel, or Riga timber, and 7l. 10s. for American yellow fir, which is conceived to be quite good enough for the purpose.

As to the Expense of Erecting the Bridge, including the Paving. 
-The Cementitious Bridge is calculated at 246,085l. without the statues.

The Bonded Bridge is calculated at $359,550 l$. without the statues.

Add to either the expense of the statues done by a first-rate artist, of granite including bases.

Number, 8 , at $400 l . . . .3200 l$.

Neither the preparation for lamps nor the making the access or paving beyond the abutments of the bridge are included.

\begin{tabular}{|c|c|c|}
\hline \multicolumn{2}{|c|}{$\begin{array}{ll} & \text { Cementitious Bridge. } \\
\text { Brought down } & \text {........... } £ 246,085\end{array}$} & $\begin{array}{l}\text { Bonded Bridge. } \\
£ 359,550\end{array}$ \\
\hline 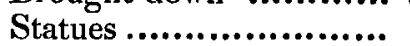 & 3,200 & 3,200 \\
\hline $\begin{array}{l}\text { Coffre-dams and accidents } \\
\text { to be supposed, and in- } \\
\text { cluding part calculated } \\
\text { to be used again........ }\end{array}$ & 72,000 & 72,000 \\
\hline $\left.\begin{array}{l}\text { Add piling if requisite, } \\
\text { calculated throughout }\end{array}\right\}$ & 36,000 & 36,000 \\
\hline & &, 750 \\
\hline
\end{tabular}

\section{To John White, Esq.}

Sir,-Your packet reached me safely yesterday; and I embrace the earliest leisure opportunity of examining your papers. If any motives in addition to those furnished by the interesting nature of the papers themselves, and the momentous topics to which they relate, had been needed to draw my attention to them, the name of my greatly esteemed friend your excellent brother would at once have turned the scale.

Complying so far as I am able with your wish, in reference to promptness, I have examined the papers this evening. The thoughts suggested by their perusal have been put down much more crudely and hastily than I could wish; but I had no alternative between writing thus, and availing myself of a delay of some days, perhaps weeks.

Both departments of your researches lay open a wide field for inquiry. I hope you will explore them thoroughly. My hints will I fear be of little, if any, utility in your pursuit: such as they are, they are at your service. I regard myself, however, as quite incompetent to speak of your designs for the bridge unless I could see the drawings. And even if I had that advantage I am by no means certain that my humble judgement in the general question would be of any value. I have a great fondness for this class of researches, but no time to pursue them. 
"The City," I fear, do not proceed in the wisest possible way with regard to this important edifice.

I have the honour to be, Sir, yours very faithfully,

Royal Military Academy,

Olinthus Gregory.

March 13, 1823.

Observations suggested by the perusal of Mr. John White's Paper on the Waterfall under London Bridge, and of his yeneral Remarks on Designs for London Bridge. By

Olinthus Gragory.

In reference to the first of these, I have long felt surprised, as Mr. White seems also to have done, that in the various proposals for erecting a new bridge, it seems scarcely ever, if at all, to have been thought worth inquiring how far the river itself may be improved or injured by peculiarities in the structure that shall be adopted.

My opinion has long been, that whether the number of arches be five or seven, it would be by no means difficult to adopt such a system of lockage, by sluices under the several arches (sometimes to be all open, at others all shut, at others part open, the rest shut, , as would serve greatly to improve the state of the river, especially above Bridge, by removing deposits of sand and filth, and giving greater uniformity to the bed of the river than it has, perhaps, possessed for centuries.

It would be easy to elucidate the comparative effect of different schemes, by models constructed " to scale," in which water should be conveyed mechanically with assigned velocities through a channel in which obstacles precisely analogous to the piers and sluices should be placed; and the operation of the moving stream (whether upward or downward) upon artificial sand or mud banks might be shown.

I have heard nothing but very vague accounts of the sluices of Catwyk, of which Mr. White speaks; and therefore am incompetent to speak of the way in which sluices at the proposed new bridge might be assimilated to it.

With regard to Mr. White's questions, I should be inclined to answer the first in the affirmative; the second in the affirmative; the third, negative; fourth, affirmative; fifth, negative; sixth, answer not partial.

The questions, however, deserve an ample consideration; and I am glad to learn that $\mathrm{Mr}$. White's ideas on a subject so momentous are nearly matured.

I am quite of opinion with $\mathrm{Mr}$. White, that the fears entertained by many persons as to the increased height of tide above the bridge, if the present structure were removed, are in a great measure groundless. The reasoning of Mr. Robert- 
son of Christ's Hospital, in 1754, as to this point, still retains all its force: "Whatever obstacles (he says) are laid in the way of the tide, across any channel, the utmost rise or high-water mark at different times will be respectively the same; because the water will continue to rise till the fixed quantity of tide is disposed of and no longer, and in like manner the low-water mark will not be affected by such obstacles."

If the present London Bridge were away, the tide of flood would be disposed of, and attain its greatest height sooner than it now does; and below Bridge the water wonld not rise quite so high. The ebb-tide would in like manner be disposed of sooner; so that the general effect would not vary materially from what it now is. By regulating sluices applied to a new bridge, both the rise and the fall might be so modified as to produce the most salutary results.

With regard to the proposed designs for the new bridge, it seems quite impossible to speak with adequate precision, independently of an inspection of the plans, elevations, \&c.

Thus much, however, may be remarked; viz. that whether the "cementitious," or the "bonding" principle be adopted, it will not be safe in arches of so large a span as from 120 to 160 feet, to disregard the consideration of the gravitating tendency of the superincumbent masses and the resulting theory of equilibration. In arches of small or moderate spans, considerable deviations from the relative dimensions prescribed by the theory of equilibration are admissible; because the inequalities of pressure thereby introduced are always far within the measure of the modulus of fracture. But in very wide arches, I should entertain considerable apprehensions of risk in any case where the curve of equilibration due to the structure did not actually fall within the materials of the arch.

The cementitious principle is doubtless susceptible of a more extensive application than it has met with in modern times. Have any experiments been instituted with a view to determine after two or more masses of stone have been thus united (say for a month or six weeks), what weight will tear the particles of cement asunder by hanging; or what will destroy the useful cohesion by pressing downwards upon the substance united?

On the whole, I should, for so capacious an arch, be disposed to prefer that upon the principle of bonding, provided the materials of the structure can be so arranged (which is a practical question) that no one or more of the separate stones shall be allowed to act with a mechanical disadvantage upon others whether near or remote.

N.S. Vol. 11. No. 63. March 1832.

$2 \mathrm{C}$ 
If the plan and elevation show the dimensions of the constituent parts, and the disposition of the several courses, they will at once remove all doubts on this head.

April 5, 1823.

If the paper on the plans for erecting a new London Bridge, distinguished by the signature "Amicus," and the letter addressed to the Comptroller of the Bridge House Estates, be laid before the Committee of the House of Commons, they will of course be accompanied by the requisite plans and elevations. But besides these, I think it would be adviseable to send with them a letter, addressed to the Chairman of the Committee of the House of Commons, in which he should be informed as briefly as possible, that these two papers were laid before the Bridge House Committee, and that the author of them offered to lay before that Committee a third communication, in which his ideas should be further developed; but that they refused to receive any further communication. That you now, therefore, beg to solicit the attention of the Committee of the House of Commons to the same subject, hoping that you will be able to convince them that a bridge upon the cementitious principle, while it should possess all desirable elegance, would be at least as durable as any other structure that could be proposed, and would also be cheaper by about a fourth of the whole sum, than an elegant, commodious and durable bridge, erected upon any other plan.' You should also advert concisely to the advantages that would result from the adoption of a proper system of lockage, as more fully explained in the second paper. And query,-should you not add that you are ready to give the Committee personally any further explanations they may require?

Dr. Gregory also suggests, that it would be a very great advantage if the road could be carried nearly on a level to a point someway up Fish-street Hill, with an arch underneath, allowing carts, \&c. to pass from Thames-street, without obstructing the passengers over the bridge.

[To be continued.]

XXV. On Electro-Magnets. By W. STURGeon, Lecturer on Experimental Philosophy at the Honourable East India Company's Military Academy, Addiscombe.*

WHEN first I showed that the magnetic energies of a galvanic conducting wire are more conspicuously exhibited

* Communicated by the Author. 

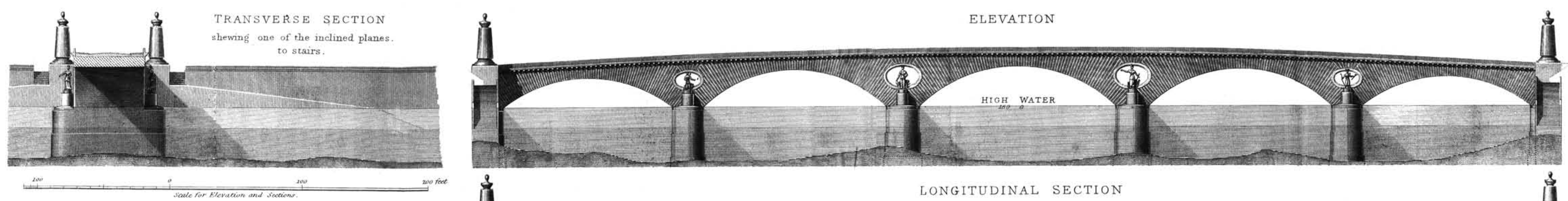

REDUCTION OF THE PROPOSED DESIGN BY JOHN WHITE

FOR THE REBUILDINC OF

COMMITTEE OF THE HOUSE OF COMMONS APRIL $11^{\text {th }} 1823$
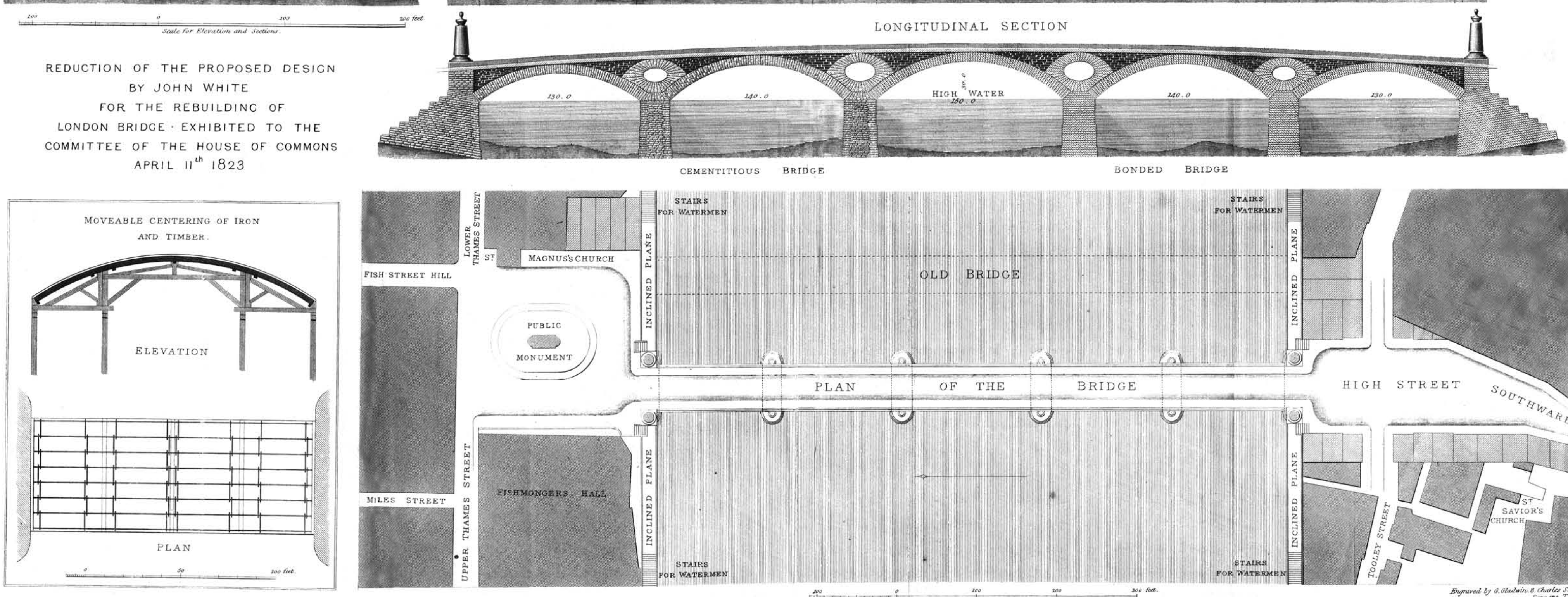

CEMENTITIOUS BRIDGE

BONDED BRIDG
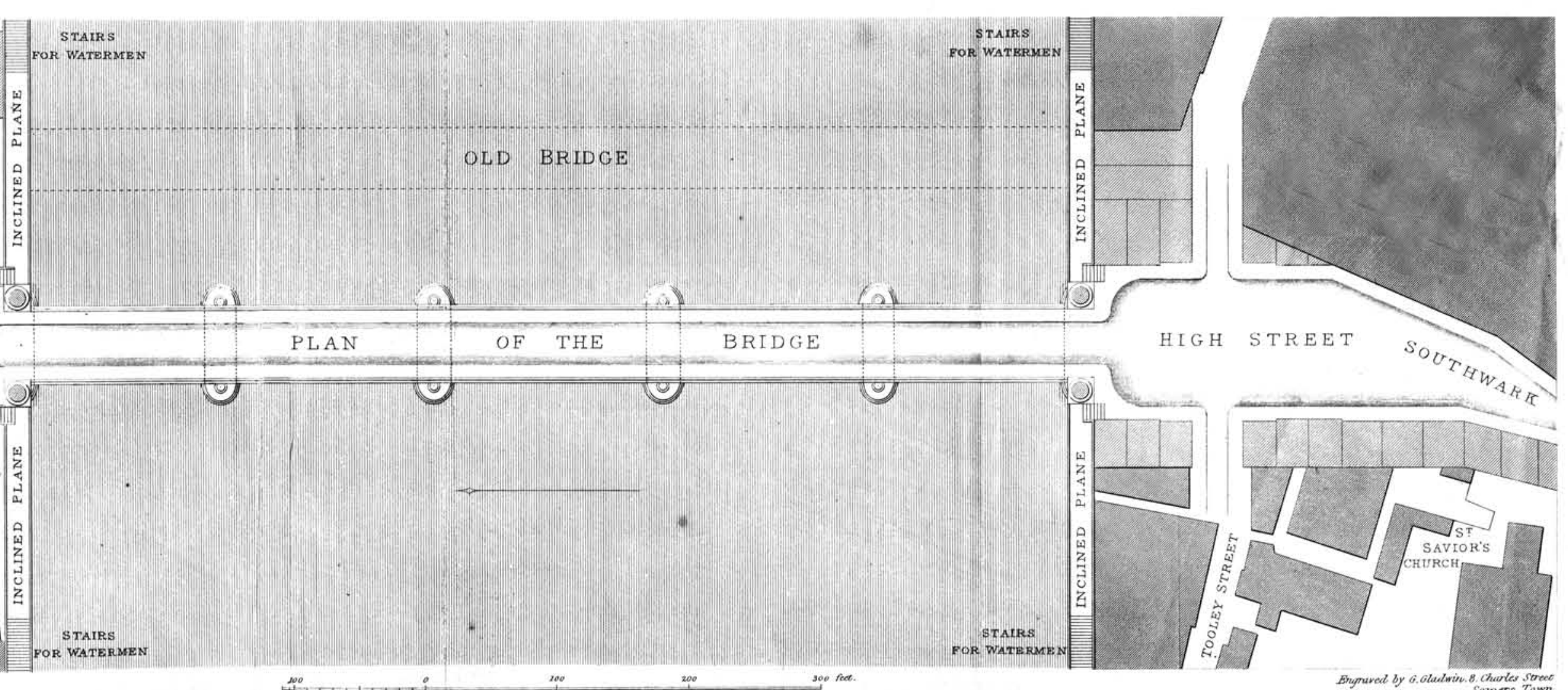